\title{
ROR $\gamma t$ Inhibitor-SR1001 Halts Retinal Inflammation, Capillary Degeneration, and the Progression of Diabetic Retinopathy
}

\author{
Thomas E. Zapadka ${ }^{1,2}$, Sarah I. Lindstrom ${ }^{1}$, Brooklyn E. Taylor ${ }^{1}$, Chieh A. Lee ${ }^{1}$, Jie Tang ${ }^{1}$, \\ Zakary R. R. Taylor ${ }^{1}$, Scott J. Howell ${ }^{1}$ and Patricia R. Taylor ${ }^{1,2, *}$ \\ 1 Department of Ophthalmology and Visual Sciences, Case Western Reserve University, School of Medicine, \\ Cleveland, OH 44106, USA; tez9@case.edu (T.E.Z.); sx1926@case.edu (S.I.L.); taylo465@miamioh.edu (B.E.T.); \\ chiehallen_lee@yahoo.com (C.A.L.); jxt50@case.edu (J.T.); zxt154@case.edu (Z.R.R.T.); \\ showell144@gmail.com (S.J.H.) \\ 2 Louis Stokes Cleveland VA Medical Center, Cleveland, OH 44106, USA \\ * Correspondence: prt11@case.edu; Tel.: +216-368-5821
}

Received: 30 April 2020; Accepted: 15 May 2020; Published: 17 May 2020

\begin{abstract}
Diabetic retinopathy is a diabetes-mediated retinal microvascular disease that is the leading cause of blindness in the working-age population worldwide. Interleukin (IL)-17A is an inflammatory cytokine that has been previously shown to play a pivotal role in the promotion and progression of diabetic retinopathy. Retinoic acid-related orphan receptor gammaT (ROR $\gamma t)$ is a ligand-dependent transcription factor that mediates IL-17A production. However, the role of ROR $\gamma \mathrm{t}$ in diabetes-mediated retinal inflammation and capillary degeneration, as well as its potential therapeutic attributes for diabetic retinopathy has not yet been determined. In the current study, we examined retinal inflammation and vascular pathology in streptozotocin-induced diabetic mice. We found ROR $\gamma t$ expressing cells in the retinal vasculature of diabetic mice. Further, diabetes-mediated retinal inflammation, oxidative stress, and retinal endothelial cell death were all significantly lower in $\mathrm{ROR} \gamma \mathrm{t}^{-/-}$mice. Finally, when a ROR $\gamma \mathrm{t}$ small molecule inhibitor (SR1001) was subcutaneously injected into diabetic mice, retinal inflammation and capillary degeneration were ameliorated. These findings establish a pathologic role for ROR $\gamma \mathrm{t}$ in the onset of diabetic retinopathy and identify a potentially novel therapeutic for this blinding disease.
\end{abstract}

Keywords: diabetic retinopathy; ROR $\gamma t$; SR1001; retinal inflammation; capillary degeneration

\section{Introduction}

Diabetes mellitus affects millions of individuals across the globe and its prevalence is on the rise. Recent predictions estimate that by 2045 nearly 630 million people will be diagnosed with diabetes [1]. As diabetes progresses, more than $60 \%$ of Type II and $95 \%$ of Type I diabetics develop diabetic retinopathy. Making diabetic retinopathy the leading cause of blindness in the working-age population worldwide [2]. Diabetes-mediated hyperglycemia induces chronic, low-grade inflammation that elicits gradual, asymptomatic alterations in the retinal microvasculature. Inflammation initiates blood-retina-barrier (BRB) permeability, immune cell leukostasis, and oxidative stress [3-6]. This causes capillary non-perfusion, which is one of the earliest detectable signs of clinical non-proliferative diabetic retinopathy $[7,8]$. In response to this vasoregression, angiogenesis of retina vessels is induced, leading to proliferative diabetic retinopathy and vision loss [9-11].

Diabetes induces Interleukin (IL)-17A production, which is one of the most prevalent cytokines associated with inflammatory pathogenesis [12]. In Type I diabetes, an autoimmune dysfunction initiates the differentiation of Th17 cells that destroy $\beta$ cells in the pancreatic islets, impairing insulin 
secretion and glucose metabolism [13,14]. In Type II diabetes, a dysfunction in adipocytes initiates IL-6 and excess leptin production, which promotes the differentiation of Th17 cells [15-17]. Persistence of circulating Th17 cells and IL-17A in both Type I and Type II diabetics has been correlated to the onset and progression of diabetic complications [18-22]. Further, in diabetic mice it was determined that IL-17A played a pivotal role in BRB permeability, vascular impairment, and the onset of non-proliferative diabetic retinopathy [23-26].

Retinoic acid-related orphan receptor gammaT $(\mathrm{ROR} \gamma \mathrm{t})$ is a ligand-dependent transcription factor that mediates IL-17A production [12,27]. When activated, ROR $\gamma \mathrm{t}$ translocates to the nucleus and binds to the Il17 gene, which up-regulates transcription and production of IL-17A [28]. In diabetes, a combination of inflammation and hyperglycemia activates ROR $\gamma \mathrm{t}$ [27]. Although the role of ROR $\gamma \mathrm{t}$ in the onset of diabetic retinopathy is not yet known, there is evidence that links $R O R \gamma t$ to the progression of other diabetic complications and retinal neovascularization in oxygen induced retinopathy [29-32]. Taken together, we postulated that ROR $\gamma \mathrm{t}$ plays a pivotal role in the pathogenesis of non-proliferative diabetic retinopathy. Further, it was our goal to identify a potential therapeutic that would delay the onset of diabetic retinopathy and inhibit vision loss.

In the current study, ROR $\gamma$ t expressing cells were detected in the sera and retinal vasculature of streptozotocin (STZ)-induced diabetic mice. Ablation of $\mathrm{ROR} \gamma \mathrm{t}$ in $\mathrm{ROR} \gamma \mathrm{t}^{-/-}$diabetic mice significantly decreased retinal inflammation, oxidative stress, and retinal endothelial cell death. These observations were extended by therapeutically administering a ROR $\gamma \mathrm{t}$ small molecule inhibitor-SR1001 to diabetic mice, wherein blocking ROR $\gamma \mathrm{t}$ activity impaired retinal capillary degeneration. These are the first findings to establish a pathologic role for ROR $\gamma t$ in diabetes-mediated retinal capillary non-perfusion, as well as identify a potentially novel therapeutic for the onset and progression of diabetic retinopathy.

\section{Results}

\subsection{Hyperglycemia in STZ-Induced Diabetic Mice}

Diabetes-mediated hyperglycemia was sustained throughout a 2-month ( $n=20 /$ group) or an 8 -month ( $n=7 /$ group) period in STZ-induced diabetic mice. Fasted $(6 \mathrm{~h})$ blood glucose levels were measured 17 days after the last STZ-injection to confirm diabetic conditions, whereas all diabetic groups had an average blood glucose level of $\sim 480 \mathrm{mg} / \mathrm{dl}$ (Figure 1A). Non-fasted blood glucose levels were also quantified at week 6 and 29, wherein glucose levels were $>600 \mathrm{mg} / \mathrm{dl}$ (data not shown). Further, sera were evaluated in non-diabetic and STZ-diabetic mice to quantify A1c levels of hyperglycemia at week 6 and 29. The severity of hyperglycemia was similar (with no significant differences) among diabetic wild type (C57BL/6), ROR $\gamma \mathrm{t}-\mathrm{GFP}$, and ROR $\gamma \mathrm{t}^{-/-}$mice, as well as SR1001 treated diabetic C57BL/6 mice (Figure 1B,C).
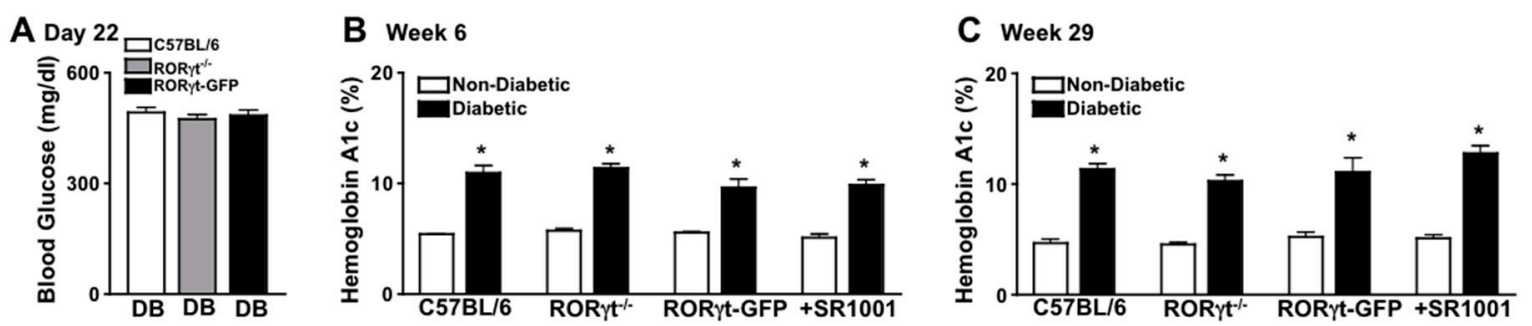

Figure 1. Hyperglycemia in streptozotocin (STZ)-induced diabetic C57BL/6 and Retinoic acid-related orphan receptor gammaT (ROR $\gamma \mathrm{t}$ ) transgenic mice. (A) Assessment of 6-h fasted Blood Glucose in diabetic C57BL/6 (white), ROR $\gamma \mathrm{t}^{-/-}$(grey), and ROR $\gamma \mathrm{t}$-GFP (black) mice ( $n=20 /$ group), 17 days after STZ injections (Day 22). Glycated Hemoglobin A (A1c) in non-diabetic (white) and STZ-induced diabetic (black) mice at 6 weeks (A) and at 29 weeks (C) after diabetic conditions were confirmed in C57BL/6, ROR $\gamma \mathrm{t}^{-/-}$, ROR $\gamma \mathrm{t}-\mathrm{GFP}$, and SR1001 treated mice. Error bars represent the standard error of the mean $(\mathrm{SEM})$, and ${ }^{*} p<0.01$. Data are representative of three separate experiments. 


\subsection{ROR $\gamma t$ Expressing Cells in the Retinal Vasculature of Diabetic Mice}

To detect cells that express ROR $\gamma \mathrm{t}$ in the retinal vasculature, we examined retinas of reporter mice that express functional ROR $\gamma t$ reported by GFP expression (ROR $\gamma \mathrm{t}-\mathrm{GFP}$ mice). Vessels were perfused, stained red with Rhodamine, and retina whole mounts were examined microscopically for the presence of ROR $\gamma \mathrm{t}$-GFP cells. As shown in representative images, ROR $\gamma \mathrm{t} / \mathrm{GFP}^{+}$cells were adhered to the retinal vasculature of diabetic, but not non-diabetic mice (Figure 2A). To quantify the cells, retinas were digested, and cells of the retina and retinal vasculature were analyzed by flow cytometry analysis. No ROR $\gamma \mathrm{t} / \mathrm{GFP}^{+}$cells were detected in the retinas of non-diabetic mice; however, $3.8 \%$ of total cells in the retina and retinal vasculature of diabetic mice were $\mathrm{ROR} \gamma \mathrm{t} / \mathrm{GFP}^{+}$(Figure $2 \mathrm{~B}$ ). Similar results identifying ROR $\gamma \mathrm{t}$ expressing cells in diabetic retinas were observed in five separate samples (Figure 2C).
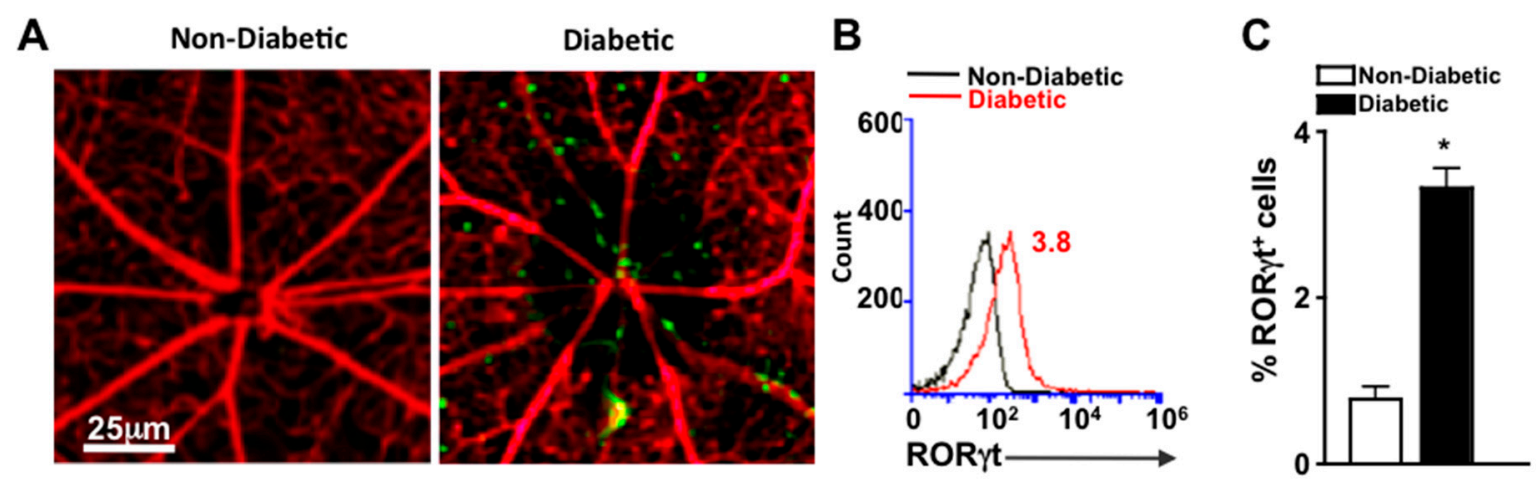

Figure 2. ROR $\gamma \mathrm{t}-\mathrm{GFP}^{+}$cells in the retinal vasculature (A) Representative fluorescent microscopy images of ROR $\gamma \mathrm{t} / \mathrm{GFP}^{+}$cells in retinas of non-diabetic and diabetic ROR $\gamma \mathrm{t}$-GFP reporter mice ( $n=3 /$ group) following perfusion and vascular staining (scale bars of all images $=25 \mu \mathrm{m}$, which is a visual indicator of the size of the representative image). (B) Representative flow cytometry overlay of ROR $\gamma \mathrm{t} / \mathrm{GFP}^{+}$ cells in the retina vasculature of non-diabetic (black) and STZ-induced diabetic (red) ROR $\gamma \mathrm{t}-\mathrm{GFP}$ mice. (C) Flow cytometry quantification $(n=5$ pooled samples ( 15 mice)/group) of percent positive (of 10,000 events) ROR $\gamma \mathrm{t} / \mathrm{GFP}^{+}$cells in retinas of non-diabetic (white) and diabetic (black) ROR $\gamma \mathrm{t}-\mathrm{GFP}$ mice. Error bars represent the SEM, and * $p<0.01$ per unpaired student's t-test. All data was collected 2 months after diabetes was confirmed. Data are representative of two separate experiments with similar results.

\subsection{Systemic Ablation of ROR $\gamma$ t Decreases Retinal Oxidative Stress and Inflammation}

To ascertain the role of ROR $\gamma \mathrm{t}$ in retinal oxidative stress during diabetes, reactive oxygen species (ROS) was quantified 2 months after diabetic conditions were confirmed in C57BL/6 and ROR $\gamma \mathrm{t}^{-/-}$ mice $(n=3)$. ROS was significantly increased in the retinas of diabetic compared with non-diabetic mice, which was significantly lowered in the diabetic ROR $\gamma \mathrm{t}^{-/-}$mice (Figure 3A). Additionally, the levels of ROS in the retinas of diabetic ROR $\gamma \mathrm{t}^{-/-}$mice were similar to that of all non-diabetic mice (Figure 3A).

To evaluate the role of ROR $\gamma t$ in diabetes induced retinal inflammation, inflammatory proteins previously identified as precursors to the onset of diabetic retinopathy (IL-17A, TNF- $\alpha$ (Tumor Necrosis Factor-alpha), and VEGF (Vascular Endothelial Growth Factor)) were examined [5,21]. Retinal protein lysates from diabetic C57BL/6 and ROR $\gamma \mathrm{t}^{-/-}$mice $(n=3)$ were collected 2 months after diabetic conditions were confirmed, and levels of IL-17A, TNF- $\alpha$, and VEGF were quantified by ELISA analysis. As shown in Figure 3B-D, 140 pg/mL of IL-17A, $125 \mathrm{pg} / \mathrm{mL}$ of TNF- $\alpha$, and $\sim 135 \mathrm{pg} / \mathrm{mL}$ of VEGF were detected in the retinas of diabetic wild type (C57BL/6) mice. Conversely, all inflammatory proteins were significantly decreased in the retinas of diabetic ROR $\gamma \mathrm{t}^{-/-}$mice, whereas only negligible levels of IL-17A (Figure 3B), $\sim 25 \mathrm{pg} / \mathrm{mL}$ of TNF- $\alpha$ (Figure 3C), and $\sim 20 \mathrm{pg} / \mathrm{mL}$ of VEGF (Figure 3D) were detected. 
Similar results were detected in a separate replicated experiment. Taken together, these results signify a role for ROR $\gamma t$ in diabetes-mediated retinal inflammation and oxidative stress.
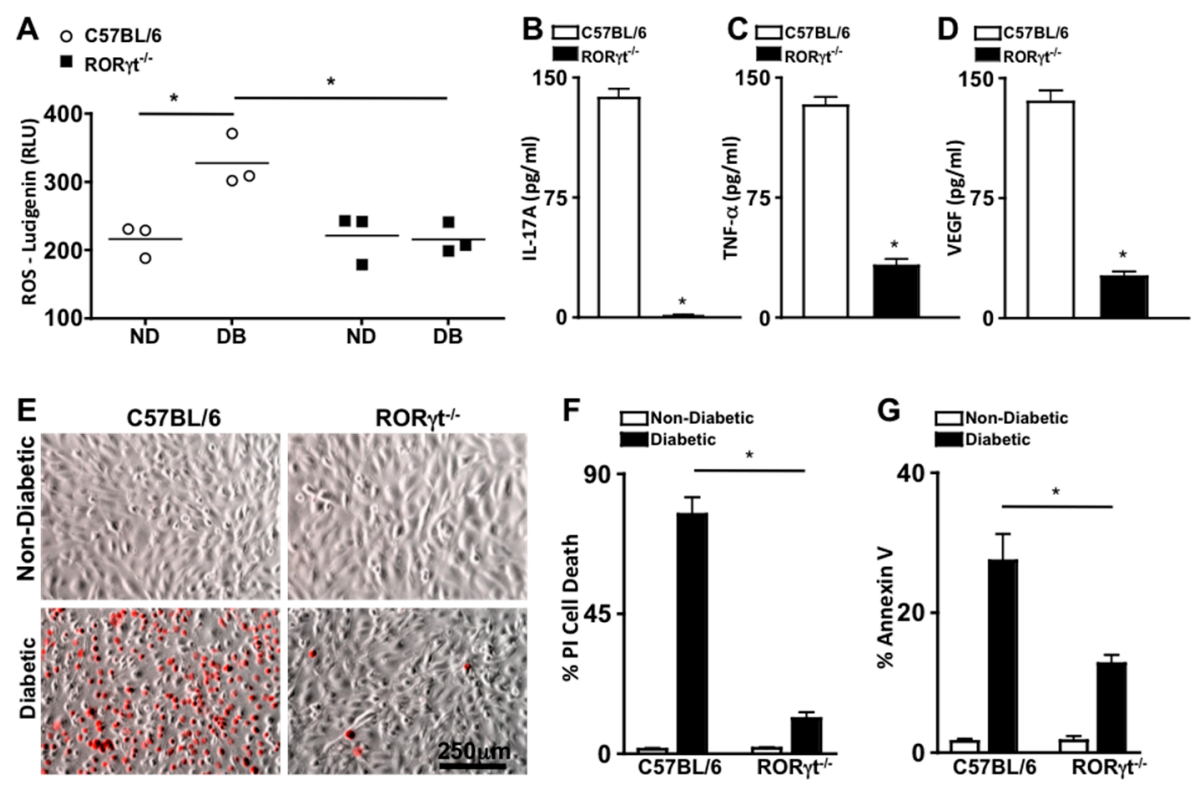

Figure 3. Oxidative stress, retinal inflammation, and endothelial cell death in retinas. (A) Quantification of reactive oxygen species (ROS) in the retinas of non-diabetic (ND) and diabetic (DB) C57BL/6 (white circles) and $\mathrm{ROR} \gamma \mathrm{t}^{-/}$(black squares) mice; each data point represents an individual retina $(n=3)$. ELISA quantifications of IL-17A (B), TNF- $\alpha(\mathbf{C})$, and VEGF (D) in retinas $(n=3)$ of diabetic C57BL/6 (white) and ROR $\gamma \mathrm{t}^{-/-}$(black) mice. ROS and inflammatory protein analysis were performed 2 months after diabetic conditions were confirmed. (E) Representative images of murine retinal endothelial cells (mREC) co-cultured with T cells of non-diabetic (top) and diabetic (bottom) C57BL/6 or ROR $\gamma \mathrm{t}^{-/-}$mice $48 \mathrm{~h}$ after incubation; dead red cells are Propidium iodide (PI) positive (scale bars of all images $=250 \mu \mathrm{m}$, which is a visual indicator of the size of the representative images). Flow cytometry quantifications of percent $\mathrm{CD} 144^{+} / \mathrm{PI}^{+}$cell death $(\mathbf{F})$ or Annexin $\mathrm{V}^{+}$apoptosis $(\mathbf{G})$ in mREC co-cultured $(n=6)$ with T cells of non-diabetic (white) or diabetic (black) C57BL/6 or ROR $\gamma \mathrm{t}^{-/-}$mice. Percent positive cells are from analysis of 30,000 events. Error bars represent the SEM, and ${ }^{*} p<0.001$ per unpaired student's $t$-test.

\subsection{ROR $\gamma$ t Enhances Retinal Endothelial Cell Death}

Previously, we determined that Th17 cells adhere to the retinal vasculature, wherein they produce IL-17A that can bind to retinal endothelial cells. When IL-17A binds to its IL17R receptor, an Act1-FADD signaling cascade induces retinal endothelial cell death, vascular impairment, and the onset of non-proliferative diabetic retinopathy in diabetic mice [25,26]. In the current study, we detected ROR $\gamma t$ expressing cells migrating through and adhered to the retinal vasculature of diabetic mice (Figure 2A). Since T cells are the most prevalent ROR $\gamma$ t expressing cell [12,27], we wanted to further determine the role of ROR $\gamma \mathrm{t}^{+} / \mathrm{T}$ cells in retinal endothelial cell death. Hence, we co-cultured murine retinal endothelial cells (mREC) with T cells from non-diabetic and diabetic C57BL/6 or ROR $\gamma \mathrm{t}^{-/-}$mice, stained the cells with Propidium iodide ((PI), which is a red indicator for membrane permeability seen in dead cells), and examined mREC cell viability by live cell images (Figure 3E) and flow cytometry analysis (Figure 3F). After $48 \mathrm{~h}$, there was a significant increase in retinal endothelial cell death $\left(\mathrm{CD} 144^{+} / \mathrm{PI}^{+}\right)$in mREC co-cultured with diabetic than non-diabetic T cells (Figure 3F). Yet, as shown in Figure 3F, there was a significant decrease in retinal endothelial cell death in mREC co-cultured with T cells of diabetic ROR $\gamma \mathrm{t}^{-/-}$mice ( 11\%) than diabetic-C57BL/6 mice ( 76\%). Taken together, this indicates that ROR $\gamma \mathrm{t}^{+} /$Tcells play a role in retinal endothelial cell death, which is the hallmark for capillary non-perfusion. 
We also analyzed early stage apoptosis in co-cultured mREC with $\mathrm{T}$ cells from non-diabetic and diabetic C57BL/6 or ROR $\gamma \mathrm{t}^{-/-}$mice through Annexin V analysis. We found that $27 \%$ of $\mathrm{mREC}$ co-cultured with $\mathrm{T}$ cells of diabetic C57BL/6 mice were Annexin V positive compared to $\sim 12 \%$ of mREC co-cultured with $\mathrm{T}$ cells of diabetic ROR $\gamma \mathrm{t}^{-/-}$mice (Figure $3 \mathrm{G}$ ). Collectively, this indicates that $\mathrm{ROR} \gamma \mathrm{t}$ plays a pivotal role in diabetes-mediated apoptosis and programmed retinal endothelial cell death, which are precursors to retinal capillary non-perfusion and the onset of non-proliferative diabetic retinopathy.

\subsection{ROR $\gamma$ t Small Molecule Inhibitor-SR1001 Decreases Retinal Inflammation}

SR1001 is a small molecule inverse agonist of ROR $\gamma \mathrm{t}$, which represses transcriptional activity at the Il17 promoter and inhibits IL-17A production [33,34]. To ascertain the efficacy of SR1001 on diabetes induced IL-17A, sera of untreated non-diabetic and untreated or SR1001 treated diabetic mice were analyzed by ELISA. Diabetic C57BL/6 mice received $100 \mu \mathrm{L}$ injections of sterile saline containing 1,2 , or $5 \mu \mathrm{M}$ of SR1001. Mice received one injection per week for two months. Two months after diabetes was confirmed, sera were collected for IL-17A ELISA analysis. There were no differences in body weight, lethargy, mortality rate, respiratory stress, or organ appearance in the SR1001 treated mice compared to the untreated mice. As shown in Figure 4A, there was only negligible levels of IL-17A detected in the sera of non-diabetic mice, which was significantly increased to $\sim 140 \mathrm{pg} / \mathrm{mL}$ in the sera $(n=3)$ of untreated diabetic mice, and diabetic mice that received 1 or $2 \mu \mathrm{M}$ of SR1001 injections. However, IL-17A was significantly decreased to negligible levels in the sera of diabetic mice that received $5 \mu \mathrm{M}$ SR1001 injections (Figure 4A). Since $5 \mu \mathrm{M}$ injections of SR1001 were sufficient to ablate IL-17A in the sera of diabetic mice, and no toxic effects were observed, this treatment regimen was used throughout the remaining SR1001 treatment studies.
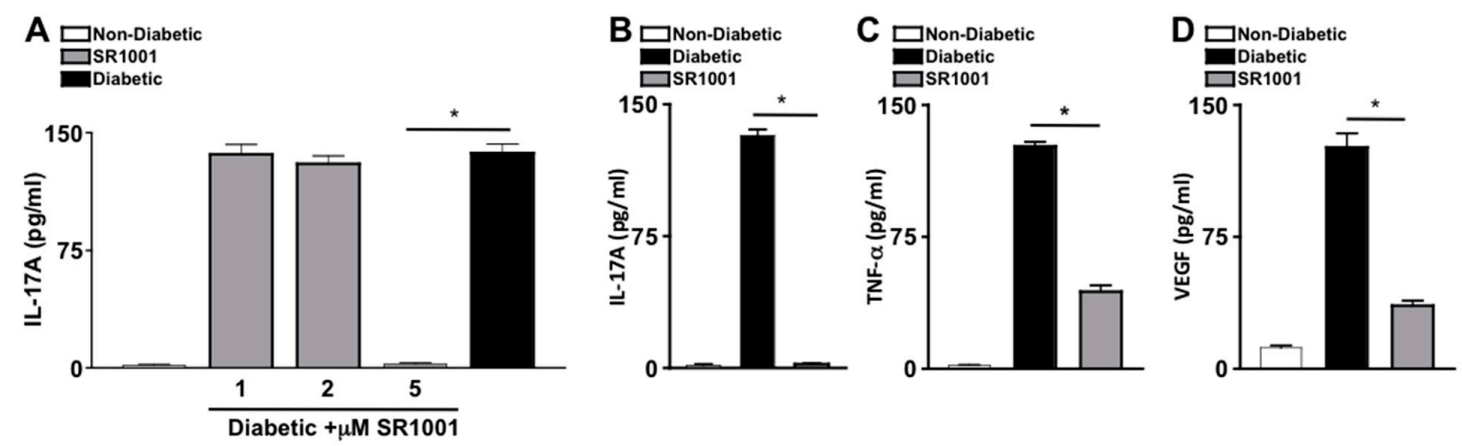

Figure 4. Inflammation in diabetic mice injected with ROR $\gamma \mathrm{t}$ inhibitor-SR1001 (A) Dose-dependent analysis of the efficacy of SR1001 to inhibit IL-17A production in sera 2 months after diabetic conditions were confirmed $(n=3)$, wherein IL-17A in the sera of non-diabetic (white), diabetic (black), or diabetic C57BL/6 mice treated with 1, 2, or $5 \mu \mathrm{M}$ of ROR $\gamma$ t inhibitor-SR1001 (grey) was quantified by ELISA. ELISA quantifications of IL-17A (B), TNF- $\alpha(\mathbf{C})$, and VEGF (D) in retinas $(n=3)$ of non-diabetic (white), diabetic (black), or diabetic treated with $5 \mu \mathrm{M}$ of SR1001 (grey) C57BL/6 mice. Error bars represent the SEM, and ${ }^{*} p<0.001$, wherein $p$-value was first equated by two-way ANOVA analysis and then an unpaired t-test with Tukey's post-hoc analysis. Data are representative of 2 separate experiments with similar results.

To further evaluate the efficacy of the ROR $\gamma \mathrm{t}$ inihibitor-SR1001 in diabetes induced retinal inflammation, levels of IL-17A, TNF- $\alpha$, and VEGF in the retina were quantified by ELISA. Retina protein lysates from untreated non-diabetic and diabetic C57BL/6 mice, as well as diabetic mice receiving weekly $5 \mu \mathrm{M}$ injections of SR1001 were analyzed by ELISA, 2 months after diabetic conditions were confirmed $(n=3)$. As shown in Figure $4 \mathrm{~B}-\mathrm{D}, \sim 130 \mathrm{pg} / \mathrm{mL}$ of IL-17A, $\sim 110 \mathrm{pg} / \mathrm{mL}$ of TNF- $\alpha$, and $\sim 125 \mathrm{pg} / \mathrm{mL}$ of VEGF were detected in the retinas of diabetic C57BL/6 mice. While only negligible levels of IL-17A (Figure $4 \mathrm{~B}$ ) and TNF- $\alpha$ (Figure $4 \mathrm{C}$ ), and $\sim 15 \mathrm{pg} / \mathrm{mL}$ of VEGF (Figure $4 \mathrm{D}$ ) were detected in the retinas of 
non-diabetic mice. Yet, all inflammatory proteins were significantly decreased in the retinas of diabetic mice receiving subcutaneous SR1001 injections, with only negligible levels of IL-17A detected. Taken together, these results identify a novel therapeutic that can inhibit retinal inflammation and potentially delay the onset of diabetic retinopathy.

\subsection{ROR $\gamma t$ Small Molecule Inhibitor-SR1001 Significantly Decreases Leukostasis in Retinas of Diabetic Mice}

Previously, it was determined that diabetes mediates leukostasis, which is the adhesion of leukocytes to the capillary endothelium and the retinal vessel walls. Leukostasis can lead to capillary non-perfusion and vascular impairment in the retina [4]. To ascertain the efficacy of SR1001 in this early stage vascular pathology in the retina, vessels were perfused, adherent cells and retinal vasculature was stained green with FITC, flat mounts of retinas were imaged by fluorescent microscopy, and the number of adherent leukocytes were manually quantified. As shown in representative images (red arrows highlight the adherent leukocytes), there were very few leukocytes adhered to the retinal vasculature in non-diabetic mice, but a significantly higher number of adherent leukocytes were detected in the retinal vasculature in diabetic mice (Figure 5A). However, leukostasis was significantly decreased in the retinas $(n=3)$ of diabetic mice that received SR1001 injections compared to untreated diabetic mice (Figure 5B). These results suggest that SR1001 is sufficient to significantly decrease diabetes-mediated leukostasis and the onset of capillary non-perfusion.

A
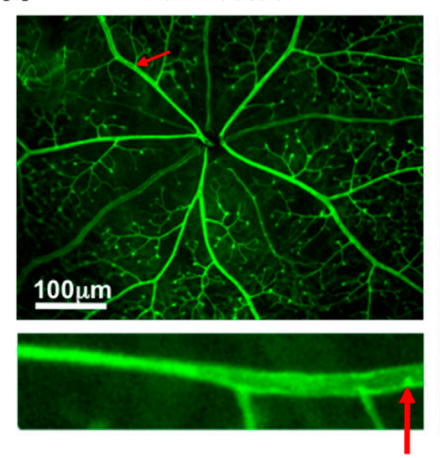

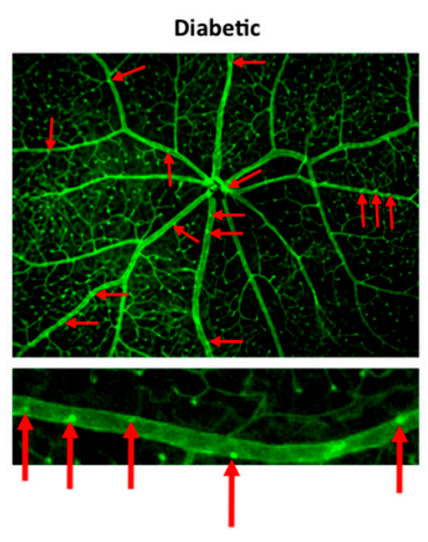

SR1001 Diabetic

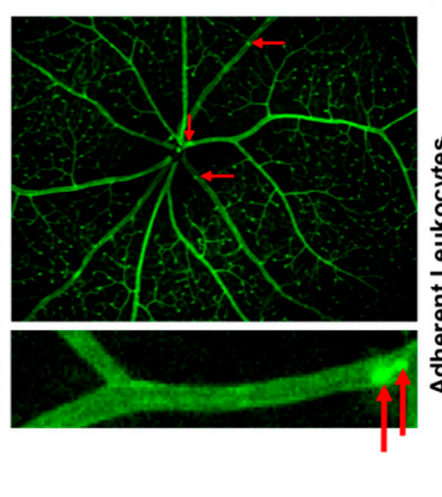

B
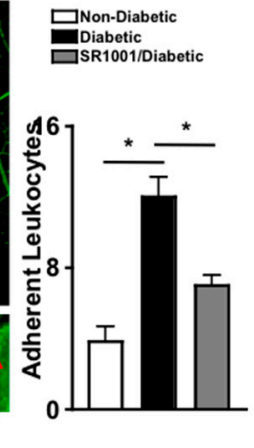

Figure 5. Leukostasis in the retinal vasculature of SR1001 treated diabetic mice. (A) Representative fluorescent microscopy images (scale bars of all images $=100 \mu \mathrm{m}$, which is a visual indicator of the size of the images) of leukocytes adhered to the retinal vasculature (highlighted by red arrows) in non-diabetic, diabetic, and SR1001 treated diabetic C57BL/6 mice following perfusion and vascular staining. Lower images are an individual retina vessel magnified $40 \times$ with adherent leukocytes highlighted by red arrows. (B) Quantification of adherent leukocytes to the vasculature in the retinas $(n=3)$ of 3 mice/group (B). Error bars represent the SEM, and $* p<0.01$, wherein $p$-value was first equated by two-way ANOVA analysis and then an unpaired t-test with Tukey's post-hoc analysis.

\subsection{SR1001 Ablates Capillary Degeneration in Diabetic Retinas}

In the early stages of diabetic retinopathy and in this 8-month murine model, endothelial cells can die in the retinal capillaries, resulting in acellular and degenerative capillaries, which leads to capillary non-perfusion [6,35]. To determine if SR1001 is sufficient to halt capillary degeneration in the diabetic retina, we isolated the capillary beds of retinas $(n=4)$ from untreated non-diabetic and diabetic C57BL/6 mice, as well as SR1001 treated diabetic mice, 8 months after diabetes was confirmed. All acellular capillaries (representative examples are highlighted by red arrows in Figure 6A) were manually quantified. The number of acellular capillaries in the retinas of diabetic mice was significantly higher than in non-diabetic mice (Figure 6B). While the number of acellular capillaries in the retinas of diabetic mice receiving SR1001 injections was significantly decreased and similar to that of non-diabetic mice 
(Figure 6B). This indicates that SR1001 is sufficient to halt diabetes-mediated capillary non-perfusion, which is the hallmark of non-proliferative diabetic retinopathy.

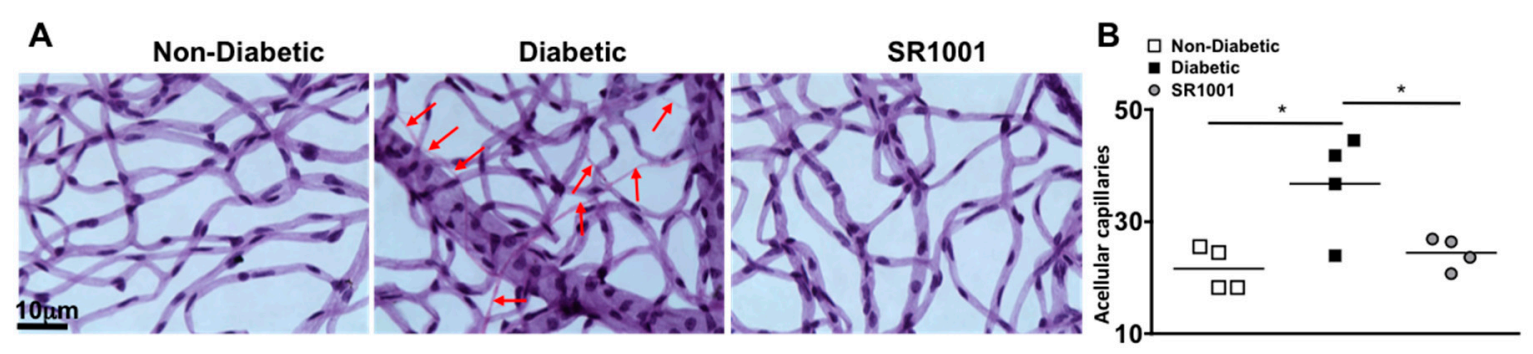

Figure 6. Acellular capillaries in the retinas of STZ-induced diabetic mice (A) Representative images of acellular capillaries and degeneration in retinal capillary beds of non-diabetic, diabetic, and SR1001 treated diabetic C57BL/6 mice (scale bars of all images $=10 \mu \mathrm{m}$, which is a visual indicator of the size of the representative images). Red arrows highlight acellular capillaries. (B) Quantification of acellular capillaries within a $1.10 \mathrm{~mm}^{2}$ area of each retina of non-diabetic (white square), diabetic (black square), and SR1001 treated diabetic (grey circle) C57BL/6 mice. Each data point represents an individual retina from 4 different mice. Error bars represent the SEM, and $p$-value was first equated by two-way ANOVA analysis and then an unpaired $t$-test with Tukey's post-hoc analysis, wherein ${ }^{*} p<0.01$. All samples were collected 8 months after diabetic conditions were confirmed.

\section{Discussion}

Diabetic retinopathy is a diabetes-mediated retinal microvascular disease, and is one of the leading causes of vision loss within the working-age population worldwide [7,35]. Gradual, asymptomatic alterations in the retinal microvasculature can lead to capillary non-perfusion and vascular leakage, which are among the earliest detectable symptoms of non-proliferative diabetic retinopathy [11]. In response to this vasoregression, neovascularization in the retina is induced, leading to proliferative diabetic retinopathy [35]. The cause of diabetic retinopathy is multifactorial, but studies over the last decade provide strong evidence that diabetes induces low-grade inflammation, which leads to oxidative stress, enhanced VEGF production, and vascular permeability in the retina. Retinal inflammation then initiates capillary non-perfusion and degeneration [36-39]. This further enhances VEGF production and downstream signaling, which initiates neovascularization in the retina that leads to vision loss [7,11]. Although anti-VEGF treatments have helped a profuse number of diabetics, many are non-responders to this treatment [40-43]. It is still unknown why some diabetics respond to anti-VEGF treatments, while there is no therapeutic effect on others. Further, there is no therapeutics for non-proliferative diabetic retinopathy. Anti-VEGF treatments and ophthalmic surgeries are performed to treat diabetic macular edema and proliferative diabetic retinopathy. Hence, we still need to identify potential therapeutic targets that would inhibit the inflammatory-mediated progression of diabetic retinopathy, and enhance the efficacy of anti-VEGF treatments.

IL-17A has been identified as an important cytokine in the promotion of diabetes and the progression of diabetic complications [22-26]. IL-17A is not constitutively produced in healthy humans, but rather it is induced in inflammatory conditions. However, clinical diabetes studies have provided evidence that IL-17A is continuously produced in the blood of both Type I and Type II diabetics [20-22]. Further, levels of IL-17A have been correlated to the progression of multiple diabetic complications in Type I and Type II diabetic patients $[19,29]$. Recently, we established a pathological role for IL-17A in the onset of non-proliferative diabetic retinopathy in Streptozotocin (STZ)-induced diabetic mice $[25,26]$. We discovered that diabetes stimulates neutrophils and Th17 cells to produce IL-17A [25]. In diabetes, IL-17A-producing cells migrate through and adhere to the retinal vasculature, wherein IL-17A crosses the blood-retina-barrier and binds to its receptor, which is expressed on photoreceptors, Muller glia, and retinal endothelial cells [23-25]. IL-17A-dependent pathogenesis is then initiated through a cascade of signaling events downstream of the IL-17A receptor $[23,26]$. 
We further discovered that IL-17A signaling in retina cells induces VEGF production, vascular leakage, and capillary degeneration in diabetic mice $[25,26]$. Others have also demonstrated a role for IL-17A in retinal neural cell pathogenesis in murine models of diabetic retinopathy [23]. In these studies, it was determined that diabetic conditions induced Muller glia to produce IL-17A. In addition to stimulating IL-17A production, hyperglycemia also enhanced the expression of the IL-17A receptor in Muller glia. Muller glia was determined to enhance neuronal apoptosis, vascular leukostasis, and vascular permeability in the retina through an autocrine signaling cascade in Muller glia [23,24]. Taken together these previous studies provide evidence that diabetes-mediated IL-17A is pivotal in the onset of diabetic retinopathy.

Also, relevant is the significance of IL-17A in anti-VEGF drug resistance. Anti-VEGF drugs are currently used to treat different types of cancers (especially renal cancer), wet age-related macular degeneration, macular edema, and diabetic retinopathy [44-48]. In all of these diseases, the efficacy of anti-VEGF drugs in many patients has been limited by intrinsic or acquired drug resistance, for unknown reasons $[49,50]$. In cancer studies, it was determined that anti-VEGF resistance is driven by tumor-secreted factors, and that IL-17A was the most abundant protein secreted by tumor resistant cells [49-51]. Further studies showed that the use of anti-IL-17A significantly improved the antitumor activity of anti-VEGF treatments [50]. Although the mechanism has not yet been fully identified, it is known that IL-17A neutralization restores the efficacy of anti-angiogenic VEGF treatment in tumorigenesis [50]. Similarly, diabetes-mediated IL-17A enhances VEGF production, which probably leads to neovascularization seen in proliferative diabetic retinopathy. Hence, all therapeutic targets that could halt IL-17A production and IL-17-dependent retinal pathogenesis could be a potential therapeutic that could enhance the efficacy of anti-VEGF treatment, and delay the onset of diabetic retinopathy. Since diabetes-mediated IL-17A production is ROR $\gamma \mathrm{t}$ dependent, and there is a ROR $\gamma \mathrm{t}$ small molecule inhibitor (SR1001) that can pass the blood-retina-barrier, we postulated that ROR $\gamma \mathrm{t}$ would be a good therapeutic target and SR1001 would be a good drug candidate for the treatment of diabetic retinopathy. Accordingly, we examined the role of ROR $\gamma t$ in the onset and progression of diabetic retinopathy, while also examining the potential of SR1001 as a therapeutic for diabetic retinopathy in this current study.

The RORC gene transcribes ROR $\gamma \mathrm{t}$, which is a protein that binds to DNA and act as a transcription factor in a ligand-dependent fashion [33,52]. ROR $\gamma \mathrm{t}$ is required for Th17 cell differentiation and IL-17A production [52]. Diabetes-mediated inflammation and hyperglycemia activate ROR $\gamma \mathrm{t}$, wherein hyperglycemia-driven IL-6 and glucose sensitive stimulatory factors co-activate a STAT3 signaling cascade that activates $\operatorname{ROR} \gamma \mathrm{t}[15,16]$. Activation of $\mathrm{ROR} \gamma \mathrm{t}$ then initiates nuclear translocation, where ROR $\gamma$ t binds to the promoter region of the Il17 gene, inducing IL-17A production [28]. Previous studies implicated that the ROR $\gamma \mathrm{t} / \mathrm{IL}-17 \mathrm{~A}$ axis played a pivotal role in the onset and progression of diabetic nephropathy [29,30]. Additionally, multiple IL-17A-producing cells that have been shown to play a role in the onset of diabetic retinopathy such as, microglia, neutrophils, and Th17 cells express ROR $\gamma t$ [25,31,53]. In the current study, we provide evidence that the ROR $\gamma \mathrm{t} / \mathrm{IL}-17 \mathrm{~A}$ axis plays a pivotal role in the onset of diabetic retinopathy. Specifically, when ROR $\gamma t$ was ablated in $\mathrm{ROR} \gamma \mathrm{t}^{-/-}$diabetic mice retinal inflammation was significantly decreased and oxidative stress was ameliorated. Both of these early stage retinal pathologies have been previously shown to lead to capillary non-perfusion and the onset of non-proliferative diabetic retinopathy $[4,38]$. Further, when $\mathrm{T}$ cells of diabetic wild type (C57BL/6) and $\mathrm{ROR} \gamma \mathrm{t}^{-/-}$mice were co-cultured with murine retinal endothelial cells (mREC), cell death was induced, however, mREC cell death was significantly decreased when mREC were cultured with T cells of ROR $\gamma \mathrm{t}^{-/-}$diabetic mice. This suggests that ROR $\gamma \mathrm{t}$ plays a role in retinal endothelial cell death that leads to capillary non-perfusion and degeneration, which is the hallmark of clinical non-proliferative diabetic retinopathy. These studies demonstrate that diabetes-mediated ROR $\gamma t$ can induce the onset of non-proliferative diabetic retinopathy, while previous studies determined that ROR $\gamma t$ plays a role in the onset of diabetic nephropathy. Collectively this suggests that ROR $\gamma \mathrm{t}$ would be a good therapeutic target for multiple diabetic complications. 
Structural studies of the ROR family identified a Liver X Receptor (LXR) agonist as a potent inverse agonist for ROR $\gamma t$, which led to the synthesis of SR1001 [54]. SR1001 is a 480 Da small molecule ligand that increases the affinity of co-repressors while decreasing the affinity of co-activators when it binds to ROR $\gamma \mathrm{t}$ [34]. Further, SR1001 binding induces a conformational change in ROR $\gamma \mathrm{t}$ to prevent DNA binding and transcriptional activation $[33,55]$. Previously, SR1001 treatment has delayed the onset and progression of experimental autoimmune encephalomyelitis (EAE) and multiple sclerosis (MS) in murine models [30,55]. In non-obese diabetic (NOD) mice, SR1001 treatment prevented Th17 cell differentiation and IL-17A production, which halted Type I diabetes progression and insulitis [30]. Further in oxygen induced retinopathy (OIR), SR1001 treatment was found to limit neovascularization, vascular leakage, and the production of VEGF [31,32]. In our current study, we discovered that SR1001 treatment ablated diabetes-mediated IL-17A production, which in turn significantly decreased leukostasis in the retinal vasculature, retinal inflammation, and VEGF production. Finally, SR1001 treatment ameliorated retinal capillary degeneration, which is ratified as clinical non-proliferative diabetic retinopathy in this murine model. Taken together, these results suggest that ROR $\gamma \mathrm{t}$ small molecule inihibitor-SR1001 could be a potential therapeutic for diabetic retinopathy.

There is an FDA approved anti-IL-17A drug that is currently being administered to patients by intravenous injections for treatment of plaque psoriasis, psoriatic arthritis, and ankylosing spondylitis. However, anti-IL-17A is a humanized monoclonal anti-IL-17A antibody that will not pass the blood-retina-barrier. Intravitreal injections of anti-IL-17A are still a possible therapeutic for diabetic retinopathy that we are further investigating. However, because diabetes induces systemic IL-17A production that has been determined to play a pivotal role in the progression of multiple diabetic complications, it would be beneficial to identify a therapeutic that could halt systemic IL-17-dependent pathology and cross the blood-retina-barrier. We conclude that this study provides strong evidence that ROR $\gamma \mathrm{t}$ inhibitor-SR1001 would be a good therapeutic candidate for the onset and progression of diabetic retinopathy.

\section{Materials and Methods}

\subsection{Streptozotocin (STZ)-Induced Diabetic Mice}

CWRU IACUC and LSCVAMC ACORP approved the animal protocols employed in this study. C57BL/6, ROR $\gamma \mathrm{t}-\mathrm{GFP}$ (heterozygous Rorc $^{+/ \mathrm{GPP}}$ : express functional ROR $\gamma \mathrm{t}$ that fluoresces green), and ROR $\gamma \mathrm{t}^{-/-}$(homozygous Rorc GFP/GFP: do not express functional ROR $\gamma \mathrm{t}$ ) mice were obtained from Jackson Laboratories. Diabetes was induced in 8-10-week-old male mice by intraperitoneal injections of (STZ) streptozotocin $(60 \mathrm{mg} / \mathrm{kg}$ ) on 5 consecutive days. Diabetes was defined by $6 \mathrm{~h}$ fasted blood glucose concentrations greater than $275 \mathrm{mg} / \mathrm{dl}$, which was verified using glucose-dehydrogenase-based strips 17 days after the last STZ injection (Day 22). Hyperglycemia was quantified by hemoglobin A1c levels using the Crystal Chem Mouse A1c kit; 6 weeks and 29 weeks after diabetes was confirmed. Insulin (0-0.2 U) was administered as needed to maintain proper body weight. Retinal inflammation and leukostasis analyses were performed 2 months after diabetic conditions were confirmed, while capillary degeneration analyses were performed 8 months after diabetic conditions were confirmed. As previously described, these are the optimal time points for these analyses in this murine model $[37,38,56]$.

\subsection{Retinal Vasculature Staining and Leukostasis Analysis}

Retinal vasculature was stained and leukostasis was analyzed as previously described $[4,6]$. Saline was perfused into the aorta to clear non-adherent leukocytes, then either $10 \mathrm{~mL}$ of Rhodamine (Figure 2) or Fluorescein (Figure 5) labeled Concanavalin A lectin (1 mg/mL in PBS; Vector laboratories) was perfused to stain vasculature. Retina flat mounts were imaged by fluorescent stereoscope, and the number of leukocytes adhered to the vasculature wall were counted. 


\subsection{Flow Cytometry of Retina Cells}

Retinas were digested using the Papain Dissociation System (Worthington), incubated for $2 \mathrm{~h}$ at $37^{\circ} \mathrm{C}$ in collagenase $(80 \mathrm{U} / \mathrm{mL}$; Sigma-Aldrich), and cells collected. Six retinas of three ROR $\gamma \mathrm{t}$-GFP mice were pooled for flow cytometry analysis, whereas 5 of these pooled samples were analyzed ( $n=15$ mice/group). For apoptosis analysis, the Annexin V detection kit (eBioscience) was used according to manufacturer's instructions. Cells were analyzed using a C6 Accuri flow cytometer (BD Bioscience); gates were set to isotype controls, and compensated using FlowJo software.

\subsection{Murine Retinal Endothelial Cells}

Murine retinal endothelial cells (mREC) originally were a kind gift of Dr. Nader Sheibani and isolated from the retinas of C57BL/6 mice as previously described [57]. Retinas were digested in collagenase and $\mathrm{MREC}$ were purified using magnetic beads coated with endothelial cell adhesion molecule-1, bound VE-Cadherin positive cells were isolated, and mREC purity was confirmed to be $>99 \%$ pure.

\subsection{Retinal Endothelial Cell Vviability Assays}

Murine retinal endothelial cells (mREC) were cultured at $80 \%$ confluency, as previously described $[26,36]$. Spleens were removed, a single-cell suspension was generated, and incubated in erythrocyte lysis buffer (eBioscience) for $5 \mathrm{~min}$ at $37^{\circ} \mathrm{C}$, and then washed and counted. $\mathrm{CD}^{+}$ $\mathrm{T}$ cells were negatively selected from isolated splenocytes using mouse CD3+ $\mathrm{T}$ cell enrichment columns (R\&D). Cells were washed, and $1 \times 10^{5} \mathrm{~T}$ cells of non-diabetic or diabetic C57BL/6 or $\mathrm{ROR} \gamma \mathrm{t}^{-/-}$mice were co-cultured with $3 \times 10^{5}$ murine retinal endothelial cells per well. Cells were stained with $10 \mu \mathrm{g} / \mathrm{mL}$ Propidium Iodide, incubated for $48 \mathrm{~h}$, and imaged using a Leica DMI 600B inverted microscope. Additionally, co-cultured cells were then stained with $0.25 \mu \mathrm{g} / \mathrm{tube}$ CD144 (BD Bioscience) for flow cytometry quantification of cell viability, as previously described [36]. Alternatively, co-cultured cells were incubated with Annexin V (eBioscience) antibodies for apoptosis analysis per manufacturer's directions.

\subsection{Quantification of Reactive Oxygen Species (ROS)}

Blood vessels were perfused, retinas were isolated and incubated in Krebs-HEPES buffer (with $5 \mathrm{mmol} / \mathrm{L}$ glucose) for $25 \mathrm{~min}$ at $37{ }^{\circ} \mathrm{C}$ in $5 \% \mathrm{CO}_{2}$. Luminescence was measured $5 \mathrm{~min}$ after the addition of $0.5 \mathrm{mmol} / \mathrm{L}$ lucigenin, as previously described [3].

\subsection{ELISA Analysis}

Sera or retina protein lysates were collected. Retina protein lysates were pooled from 3 retinas, and 3-pooled samples were analyzed using 2-site mIL-17A, mTNF- $\alpha$, and mVEGF ELISA according to the manufacturer's directions ( $R \& D$ Biosciences).

\subsection{ROR $\gamma$ t Small Molecule Inhibitor-SR1001 Treatment Regimen}

SR1001 is a small molecule inverse agonist of ROR $\gamma$ t. SR1001 is $\sim 480 \mathrm{Da}$, and represses transcriptional activity at the $I l 17$ promoter by inhibiting co-activator interaction and promoting the binding of co-repressors [34]. Lyophilized SR1001 was suspended in DMSO (5 mg/250 $\mu \mathrm{L})$, and diluted in sterile saline to $5 \mu \mathrm{M} / 100 \mu \mathrm{L}$ (final DMSO concentration $=0.125 \%$ ). C57BL $/ 6$ diabetic mice received weekly subcutaneous injections, which started one week after diabetic conditions were confirmed (Day 29). Mice analyzed at the 2-month time point received 7 injections, while mice analyzed at the 8-month time point received 28 injections. Toxicity parameters for SR1001 were defined by weekly body weight measures, epidemiology of lethargy and mortality rate, and organ appearance by autopsy. No toxicity was observed in any of these SR1001 treatment regimens. 


\subsection{Capillary Degeneration in the Retina}

Acellular capillaries were quantified in the retinal vasculature as previously described [6,7]. Eyes were fixed with $10 \%$ formalin. Retinas were incubated in elastase for $2 \mathrm{~h}$ followed by acidic buffer overnight. Retinal vasculature was mechanically isolated and stained with hematoxylin and periodic acid-Schiff. Acellular capillaries were quantified in 7 field areas between the optic nerve and the periphery (200×g magnification). Representative pictures were taken using a $40 \times$ objective mounted on an Olympus BX-60 microscope, using a Q-imaging Retiga Exi camera and Metamorph imaging software.

\subsection{Statistical Analysis}

Statistical analysis was performed using a two-way ANOVA and an unpaired t-test with Tukey's post-hoc analysis (Prism, GraphPad Software). A $p$-value $<0.05$ was considered significant. Error bars represent the standard error of the mean (SEM).

Author Contributions: Each author has made substantial contributions in the conception and design of this work, or acquisition, analysis, and interpretation of the data. Further, all authors have aided in drafting this manuscript, approve this submitted version, and agree to be personally accountable for their own contributions to this study. The following is each authors contributions: T.E.Z.: conceptualization, methodology, validation, formal analysis, investigation, data curation, writing original draft and preparation of the manuscript; S.I.L.: methodology, validation, formal analysis, data curation, preparation of the manuscript; B.E.T.: methodology, validation, formal analysis, data curation, preparation of the manuscript; C.A.L.: conceptualization, methodology, validation, formal analysis, data curation, preparation of the manuscript, J.T.: methodology, validation, formal analysis, data curation, preparation of the manuscript; Z.R.R.T.: methodology, validation, formal analysis, data curation, preparation of the manuscript; S.J.H.: conceptualization, methodology, validation, formal analysis, data curation, preparation of the manuscript; P.R.T.: conceptualization, methodology, validation, formal analysis, investigation, resources, data curation, writing, reviewing, and editing original draft and preparation of the manuscript, supervision, project administration, and funding acquisition. All authors have read and agreed to the published version of the manuscript.

Funding: This work was supported by the following grants: VA BX003403, RO1 EY030487, P30 EY011373, the Research to Prevent Blindness Foundation, and the Ohio Lions Eye Research Foundation.

Acknowledgments: We would like to thank Heather Butler, John Denker, Catherine Doller, Denice Major, and Dawn Smith for outstanding technical assistance. We also thank Nader Sheibani for providing the murine retinal endothelial cells.

Conflicts of Interest: The authors declare no conflict of interest.

\section{References}

1. Forouhi, N.G.; Wareham, N.J. Epidemiology of Diabetes. Medicine 2019, 47, 22-27. [CrossRef]

2. Yau, J.W.; Rogers, S.L.; Kawasaki, R.; Lamoureux, E.L.; Kowalski, J.W.; Bek, T.; Chen, S.J.; Dekker, J.M.; Fletcher, A.; Grauslund, J.; et al. Global prevalence and major risk factors of diabetic retinopathy. Diabetes Care 2012, 35, 556-564. [CrossRef] [PubMed]

3. Du, Y.; Veenstra, A.; Palczewski, K.; Kern, T.S. Photoreceptor cells are major contributors to diabetes-induced oxidative stress and local inflammation in the retina. Proc. Natl. Acad. Sci. USA 2013, 110, 16586-16591. [CrossRef] [PubMed]

4. Liu, H.; Tang, J.; Lee, C.A.; Kern, T.S. Metanx and early stages of diabetic retinopathy. Investig. Ophthalmol. Vis. Sci. 2015, 56, 647-653. [CrossRef]

5. Tang, J.; Kern, T.S. Inflammation in diabetic retinopathy. Prog. Retin. Eye Res. 2011, 30, 343-358. [CrossRef]

6. Veenstra, A.; Liu, H.; Lee, C.A.; Du, Y.; Tang, J.; Kern, T.S. Diabetic Retinopathy: Retina-Specific Methods for Maintenance of Diabetic Rodents and Evaluation of Vascular Histopathology and Molecular Abnormalities. Curr. Protoc. Mouse Biol. 2015, 5, 247-270. [CrossRef]

7. Kern, T.S.; Tang, J.; Berkowitz, B.A. Validation of structural and functional lesions of diabetic retinopathy in mice. Mol. Vis. 2010, 16, 2121-2131.

8. Rasta, S.H.; Nikfarjam, S.; Javadzadeh, A. Detection of retinal capillary nonperfusion in fundus fluorescein angiogram of diabetic retinopathy. Bioimpacts 2015, 5, 183-190. [CrossRef] 
9. Wang, W.; Lo, A.C.Y. Diabetic Retinopathy: Pathophysiology and Treatments. Int. J. Mol. Sci. 2018, $19,1816$. [CrossRef]

10. Semeraro, F.; Cancarini, A.; dell'Omo, R.; Rezzola, S.; Romano, M.R.; Costagliola, C. Diabetic Retinopathy: Vascular and Inflammatory Disease. J. Diabetes Res. 2015, 2015, 582060. [CrossRef]

11. Hammes, H.P.; Feng, Y.; Pfister, F.; Brownlee, M. Diabetic retinopathy: Targeting vasoregression. Diabetes 2011, 60, 9-16. [CrossRef] [PubMed]

12. Hirota, K.; Duarte, J.H.; Veldhoen, M.; Hornsby, E.; Li, Y.; Cua, D.J.; Ahlfors, H.; Wilhelm, C.; Tolaini, M.; Menzel, U.; et al. Fate mapping of IL-17-producing T cells in inflammatory responses. Nat. Immunol. 2011, 12, 255-263. [CrossRef] [PubMed]

13. Boehm, B.O.; Rosinger, S.; Sauer, G.; Manfras, B.J.; Palesch, D.; Schiekofer, S.; Kalbacher, H.; Burster, T. Protease-resistant human GAD-derived altered peptide ligands decrease TNF-alpha and IL-17 production in peripheral blood cells from patients with type 1 diabetes mellitus. Mol. Immunol. 2009, 46, 2576-2584. [CrossRef] [PubMed]

14. Towns, R.; Pietropaolo, M. GAD65 autoantibodies and its role as biomarker of Type 1 diabetes and Latent Autoimmune Diabetes in Adults (LADA). Drugs Future 2011, 36, 847. [CrossRef]

15. Allen, T.L.; Febbraio, M.A. IL6 as a mediator of insulin resistance: Fat or fiction? Diabetologia 2010, 53, 399-402. [CrossRef]

16. Orlova, E.G.; Shirshev, S.V. Role of leptin and ghrelin in induction of differentiation of IL-17-producing and T-regulatory cells. Bull. Exp. Biol. Med. 2014, 156, 819-822. [CrossRef]

17. Wueest, S.; Konrad, D. The role of adipocyte-specific IL-6-type cytokine signaling in FFA and leptin release. Adipocyte 2018, 7, 226-228. [CrossRef]

18. Honkanen, J.; Nieminen, J.K.; Gao, R.; Luopajarvi, K.; Salo, H.M.; Ilonen, J.; Knip, M.; Otonkoski, T.; Vaarala, O. IL-17 immunity in human type 1 diabetes. J. Immunol. 2010, 185, 1959-1967. [CrossRef]

19. Baharlou, R.; Ahmadi-Vasmehjani, A.; Davami, M.H.; Faraji, F.; Atashzar, M.R.; Karimipour, F.; Sadeghi, A.; Asadi, M.A.; Khoubyari, M. Elevated Levels of T-helper 17-associated Cytokines in Diabetes Type I Patients: Indicators for Following the Course of Disease. Immunol. Investig. 2016, 45, 641-651. [CrossRef]

20. Hang, H.; Yuan, S.; Yang, Q.; Yuan, D.; Liu, Q. Multiplex bead array assay of plasma cytokines in type 2 diabetes mellitus with diabetic retinopathy. Mol. Vis. 2014, 20, 1137-1145.

21. Semeran, K.; Pawlowski, P.; Lisowski, L.; Szczepaniak, I.; Wojtowicz, J.; Lawicki, S.; Bakunowicz-Lazarczyk, A.; Bossowski, A. Plasma levels of IL-17, VEGF, and adrenomedullin and S-cone dysfunction of the retina in children and adolescents without signs of retinopathy and with varied duration of diabetes. Mediat. Inflamm. 2013, 2013, 274726. [CrossRef] [PubMed]

22. Marwaha, A.K.; Crome, S.Q.; Panagiotopoulos, C.; Berg, K.B.; Qin, H.; Ouyang, Q.; Xu, L.; Priatel, J.J.; Levings, M.K.; Tan, R. Cutting edge: Increased IL-17-secreting T cells in children with new-onset type 1 diabetes. J. Immunol. 2010, 185, 3814-3818. [CrossRef] [PubMed]

23. Qiu, A.W.; Bian, Z.; Mao, P.A.; Liu, Q.H. IL-17A exacerbates diabetic retinopathy by impairing Muller cell function via Act1 signaling. Exp. Mol. Med. 2016, 48, e280. [CrossRef] [PubMed]

24. Qiu, A.W.; Liu, Q.H.; Wang, J.L. Blocking IL-17A Alleviates Diabetic Retinopathy in Rodents. Cell Physiol. Biochem. 2017, 41, 960-972. [CrossRef] [PubMed]

25. Sigurdardottir, S.; Zapadka, T.E.; Lindstrom, S.I.; Liu, H.; Taylor, B.E.; Lee, C.A.; Kern, T.S.; Taylor, P.R. Diabetes-mediated IL-17A enhances retinal inflammation, oxidative stress, and vascular permeability. Cell Immunol. 2019, 341, 103921. [CrossRef] [PubMed]

26. Lindstrom, S.I.; Sigurdardottir, S.; Zapadka, T.E.; Tang, J.; Liu, H.; Taylor, B.E.; Smith, D.G.; Lee, C.A.; DeAngelis, J.; Kern, T.S.; et al. Diabetes induces IL-17A-Act1-FADD-dependent retinal endothelial cell death and capillary degeneration. J. Diabetes Complicat. 2019, 33, 668-674. [CrossRef] [PubMed]

27. Ivanov, I.I.; McKenzie, B.S.; Zhou, L.; Tadokoro, C.E.; Lepelley, A.; Lafaille, J.J.; Cua, D.J.; Littman, D.R. The orphan nuclear receptor RORgammat directs the differentiation program of proinflammatory IL-17+ T helper cells. Cell 2006, 126, 1121-1133. [CrossRef]

28. Wang, X.; Zhang, Y.; Yang, X.O.; Nurieva, R.I.; Chang, S.H.; Ojeda, S.S.; Kang, H.S.; Schluns, K.S.; Gui, J.; Jetten, A.M.; et al. Transcription of Il17 and Il17f is controlled by conserved noncoding sequence 2. Immunity 2012, 36, 23-31. [CrossRef] 
29. Lavoz, C.; Matus, Y.S.; Orejudo, M.; Carpio, J.D.; Droguett, A.; Egido, J.; Mezzano, S.; Ruiz-Ortega, M. Interleukin-17A blockade reduces albuminuria and kidney injury in an accelerated model of diabetic nephropathy. Kidney Int. 2019, 95, 1418-1432. [CrossRef]

30. Solt, L.A.; Banerjee, S.; Campbell, S.; Kamenecka, T.M.; Burris, T.P. ROR inverse agonist suppresses insulitis and prevents hyperglycemia in a mouse model of type 1 diabetes. Endocrinology 2015, 156, 869-881. [CrossRef]

31. Talia, D.M.; Deliyanti, D.; Agrotis, A.; Wilkinson-Berka, J.L. Inhibition of the Nuclear Receptor RORgamma and Interleukin-17A Suppresses Neovascular Retinopathy: Involvement of Immunocompetent Microglia. Arterioscler. Thromb. Vasc. Biol. 2016, 36, 1186-1196. [CrossRef] [PubMed]

32. Sun, Y.; Liu, C.H.; SanGiovanni, J.P.; Evans, L.P.; Tian, K.T.; Zhang, B.; Stahl, A.; Pu, W.T.; Kamenecka, T.M.; Solt, L.A.; et al. Nuclear receptor RORalpha regulates pathologic retinal angiogenesis by modulating SOCS3-dependent inflammation. Proc. Natl. Acad. Sci. USA 2015, 112, 10401-10406. [CrossRef] [PubMed]

33. Burris, T.P.; Busby, S.A.; Griffin, P.R. Targeting orphan nuclear receptors for treatment of metabolic diseases and autoimmunity. Chem. Biol. 2012, 19, 51-59. [CrossRef] [PubMed]

34. Huh, J.R.; Littman, D.R. Small molecule inhibitors of RORgammat: Targeting Th17 cells and other applications. Eur. J. Immunol. 2012, 42, 2232-2237. [CrossRef]

35. Bresnick, G.H.; Davis, M.D.; Myers, F.L.; de Venecia, G. Clinicopathologic correlations in diabetic retinopathy. II. Clinical and histologic appearances of retinal capillary microaneurysms. Arch. Ophthalmol. 1977, 95, 1215-1220. [CrossRef]

36. Li, G.; Veenstra, A.A.; Talahalli, R.R.; Wang, X.; Gubitosi-Klug, R.A.; Sheibani, N.; Kern, T.S. Marrow-derived cells regulate the development of early diabetic retinopathy and tactile allodynia in mice. Diabetes 2012, 61, 3294-3303. [CrossRef]

37. Antonetti, D.A.; Barber, A.J.; Khin, S.; Lieth, E.; Tarbell, J.M.; Gardner, T.W. Vascular permeability in experimental diabetes is associated with reduced endothelial occludin content: Vascular endothelial growth factor decreases occludin in retinal endothelial cells. Penn State Retina Research Group. Diabetes 1998, 47, 1953-1959. [CrossRef]

38. Tonade, D.; Liu, H.; Palczewski, K.; Kern, T.S. Photoreceptor cells produce inflammatory products that contribute to retinal vascular permeability in a mouse model of diabetes. Diabetologia 2017, 60, 2111-2120. [CrossRef]

39. Limb, G.A.; Chignell, A.H.; Green, W.; LeRoy, F.; Dumonde, D.C. Distribution of TNF alpha and its reactive vascular adhesion molecules in fibrovascular membranes of proliferative diabetic retinopathy. Br. J. Ophthalmol. 1996, 80, 168-173. [CrossRef]

40. Gallego-Pinazo, R.; Dolz-Marco, R.; Pardo-Lopez, D.; Arevalo, J.F.; Diaz-Llopis, M. Primary intravitreal ranibizumab for adult-onset foveomacular vitelliform dystrophy. Graefes Arch. Clin. Exp. Ophthalmol. 2011, 249, 455-458. [CrossRef]

41. Arevalo, J.F.; Adan, A.; Berrocal, M.H.; Espinoza, J.V.; Maia, M.; Wu, L.; Roca, J.A.; Quiroz-Mercado, H.; Ruiz-Moreno, J.M.; Serrano, M.A. Intravitreal bevacizumab for inflammatory choroidal neovascularization: Results from the Pan-American Collaborative Retina Study Group at 24 months. Retina 2011, 31, 353-363. [CrossRef] [PubMed]

42. Osaadon, P.; Fagan, X.J.; Lifshitz, T.; Levy, J. A review of anti-VEGF agents for proliferative diabetic retinopathy. Eye 2014, 28, 510-520. [CrossRef] [PubMed]

43. Cheung, N.; Wong, I.Y.; Wong, T.Y. Ocular anti-VEGF therapy for diabetic retinopathy: Overview of clinical efficacy and evolving applications. Diabetes Care 2014, 37, 900-905. [CrossRef] [PubMed]

44. Choueiri, T.K. VEGF inhibitors in metastatic renal cell carcinoma: Current therapies and future perspective. Curr. Clin. Pharmacol. 2011, 6, 164-168. [CrossRef]

45. Goel, H.L.; Mercurio, A.M. VEGF targets the tumour cell. Nat. Rev. Cancer 2013, 13, 871-882. [CrossRef]

46. Kovach, J.L.; Schwartz, S.G.; Flynn, H.W., Jr.; Scott, I.U. Anti-VEGF Treatment Strategies for Wet AMD. J. Ophthalmol. 2012, 2012, 786870. [CrossRef]

47. Jumper, J.M.; Dugel, P.U.; Chen, S.; Blinder, K.J.; Walt, J.G. Anti-VEGF treatment of macular edema associated with retinal vein occlusion: Patterns of use and effectiveness in clinical practice (ECHO study report 2). Clin. Ophthalmol. 2018, 12, 621-629. [CrossRef]

48. Blinder, K.J.; Dugel, P.U.; Chen, S.; Jumper, J.M.; Walt, J.G.; Hollander, D.A.; Scott, L.C. Anti-VEGF treatment of diabetic macular edema in clinical practice: Effectiveness and patterns of use (ECHO Study Report 1). Clin. Ophthalmol. 2017, 11, 393-401. [CrossRef] 
49. Maniati, E.; Hagemann, T. IL-17 mediates resistance to anti-VEGF therapy. Nat. Med. 2013, 19, $1092-1094$. [CrossRef]

50. Chung, A.S.; Wu, X.; Zhuang, G.; Ngu, H.; Kasman, I.; Zhang, J.; Vernes, J.M.; Jiang, Z.; Meng, Y.G.; Peale, F.V.; et al. An interleukin-17-mediated paracrine network promotes tumor resistance to anti-angiogenic therapy. Nat. Med. 2013, 19, 1114-1123. [CrossRef]

51. Pan, B.; Shen, J.; Cao, J.; Zhou, Y.; Shang, L.; Jin, S.; Cao, S.; Che, D.; Liu, F.; Yu, Y. Interleukin-17 promotes angiogenesis by stimulating VEGF production of cancer cells via the STAT3/GIV signaling pathway in non-small-cell lung cancer. Sci. Rep. 2015, 5, 16053. [CrossRef] [PubMed]

52. Chang, M.R.; Goswami, D.; Mercer, B.A.; Griffin, P.R. The therapeutic potential of RORgamma modulators in the treatment of human disease. J. Exp. Pharmacol. 2012, 4, 141-148. [PubMed]

53. Taylor, P.R.; Roy, S.; Leal, S.M., Jr.; Sun, Y.; Howell, S.J.; Cobb, B.A.; Li, X.; Pearlman, E. Activation of neutrophils by autocrine IL-17A-IL-17RC interactions during fungal infection is regulated by IL-6, IL-23, RORgammat and dectin-2. Nat. Immunol. 2014, 15, 143-151. [CrossRef] [PubMed]

54. Xu, J.; Wagoner, G.; Douglas, J.C.; Drew, P.D. Liver X receptor agonist regulation of Th17 lymphocyte function in autoimmunity. J. Leukoc. Biol. 2009, 86, 401-409. [CrossRef] [PubMed]

55. Solt, L.A.; Kumar, N.; Nuhant, P.; Wang, Y.; Lauer, J.L.; Liu, J.; Istrate, M.A.; Kamenecka, T.M.; Roush, W.R.; Vidovic, D.; et al. Suppression of TH17 differentiation and autoimmunity by a synthetic ROR ligand. Nature 2011, 472, 491-494. [CrossRef] [PubMed]

56. Robinson, R.; Barathi, V.A.; Chaurasia, S.S.; Wong, T.Y.; Kern, T.S. Update on animal models of diabetic retinopathy: From molecular approaches to mice and higher mammals. Dis. Models Mech. 2012, 5, 444-456. [CrossRef]

57. Su, X.; Sorenson, C.M.; Sheibani, N. Isolation and characterization of murine retinal endothelial cells. Mol. Vis. 2003, 9, 171-178.

(C) 2020 by the authors. Licensee MDPI, Basel, Switzerland. This article is an open access article distributed under the terms and conditions of the Creative Commons Attribution (CC BY) license (http://creativecommons.org/licenses/by/4.0/). 